\title{
DYNAMIC ASSESSMENT OF A CURVED CABLE-STAYED BRIDGE BY MODEL UPDATING
}

James M. W. Brownjohn ${ }^{1}$ and Pin-Qi Xia ${ }^{2}$

\section{Abstract}

Bridges are indispensable components of the infrastructure of modern society and their assessment via techniques of structural dynamics is assuming greater importance. This assessment concerns performance of the as-built structure compared to the design and can also extend to assessment of structural deterioration or damage. Simple validation of numerical results by dynamic testing has met some success, but feedback from testing into analysis is usually crude, and only recently have systematic techniques been developed that can be applied to such structures.

This paper investigates the application of sensitivity-based model updating technology to the dynamic assessment of the Safti Link Bridge, a curved cablestayed bridge in Singapore. Based on the measured modal data from prototype testing, the simulated dynamic properties obtained via finite element analysis have been significantly improved by modification of uncertain structural parameters such as Young's modulus of concrete and structural geometry.

\footnotetext{
${ }^{1}$ Associate Professor, School of Civil and Structural Engineering, Nanyang Technological University, Nanyang Avenue, Singapore 639798, Tel: (65) 7904773, Fax: (65) 7910676, Email: cjames@ntu.edu.sg

${ }^{2}$ PhD Student, School of Civil and Structural Engineering, Nanyang Technological University, Nanyang Avenue, Singapore 639798, Tel: (65) 7906037, Fax: (65) 7910676,

Email: pp2906893@ntu.edu.sg
} 


\section{Key Words:}

Dynamic Assessment; Model Updating; Cable-Stayed Bridge; Finite Element Analysis; Experimental Modal Analysis; Sensitivity Analysis; Finite Element Modeling; Prototype Testing

\section{Introduction}

Cable-stayed bridges with modern distinctive styles are increasing in number worldwide. These bridges are now built in more unusual styles for structural and aesthetic reasons (Rito 1996 and Menn 1996). Examples include the Lerez Bridge (Troyano et al. 1998) - a single inclined tower bridge; the Katsushika Harp Bridge (Takenouchi 1998) - having a single pylon and S shaped deck; the Marian Bridge (Kominek 1998) - having a single L shaped pylon; the Alamillo Bridge Casa 1995), with a single inclined pylon and the Safti Link Bridge (Tan 1996) - which has a curved deck and single offset pylon. The unique structural styles of these bridges beautify the environment but also add to the difficulties in accurate structural analysis. The accurate assessment of these and other types of bridge using dynamics-based methods has become of increasing concern due to their infrastructural role.

Dynamics-based assessment (Severn et al. 1989, Felber and Cantieni 1996, Law and Ko 1995 and Felber 1995) of these unusual bridges is based on comparison of the experimental modal analysis (EMA) data obtained during full-scale tests with the finite element analysis (FEA) predictions. One purpose of the comparison is so that the finite element (FE) models can be used to predict performance during unusual loads such as earthquakes (Brownjohn et al. 1992 and Dumanoglu et al. 
1991). Even if resulting response is large enough that material and geometric nonlinearities become significant, the starting point for non-linear analysis would be a realistic linear model. For example in the case of a suspension bridge, the large cable oscillations will vary the geometric stiffness, which can be accommodated in non-linear analyses if the operating tension is known. Material non-linearities can also be incorporated based on the low level characteristics. Other motivations for dynamics-based assessment include the validation of design assumptions embodied in the FE model and health assessment i.e. the identification of structural deterioration or damage.

Confidence in using FE models for performance predictions may be lacking due to relatively large differences between experimental and analytical modes. The differences come not only from the modeling errors resulting from simplifying assumptions made in modeling the complicated structures, but also from parameter errors due to the uncertainties in material and geometric properties and boundary conditions. The simplifying assumptions depend on the intended application of the model and on the experience of the engineer. However, given an appropriate structural model, there are various methods (Mottershead and Friswell 1993) for 'forcing' a match between analytical predictions and measured responses, some of which involve direct updates to structural stiffness or mass matrices. Modification of structural parameters having clear physical significance is the preferred route.

This technique of model updating for correcting uncertainties from modeling, geometry, material and analysis to improve the analytical results based on the experimental modal results has emerged in the 1990s as a subject of great importance for mechanical and aerospace structures. It has been developed to the 
point of becoming a standard structural analysis and assessment tool for these structures. However, this updating technology is still difficult to apply as a standard engineering tool for civil engineering structures, because of the difficulties in prototype testing and experimental data analysis resulting from the nature, size, location and usage of these structures and the greater uncertainties in material physical properties. In particular for field testing of a bridge the tester is at the mercy of varying environmental conditions not limited to temperature and traffic. Without the benefit of the relatively controlled and repeatable conditions of laboratory testing the response parameters are likely to change. Moreover when relying on ambient excitation the requirements of nonstationarity for reliable spectral analysis are inevitably violated and a greater skill is required to recognise when a response is not a feature of the structure but of the excitation.

The FE model updating process has several functions in civil engineering structural dynamics. First, if the results of updating processes are disseminated to the engineering community via case studies, they can serve as a guide for further modeling of similar structures. For example consistent overestimation of foundation fixity could lead to more realistic design assumptions. Unless there is feedback from full-scale tests into the FE model, such an effect will not be unearthed. Because all civil engineering structures are prototypes, the benefit is not so immediate as is the case in mechanical and aerospace engineering where developed models can immediately be applied to the study of production variants. Second, the 'new improved' model can be used for further appraisals of the actual structure tested e.g. for predicting effects of unusual loads or of making structural modifications. In addition, increased confidence in structural modeling and the 
consequent reductions in uncertainties may lead to more economic designs. A final and increasingly important benefit is the potential for use as a damage detection technique (Doebling et al. 1998) and as a database for the bridge management systems (Hearn 1998 and Hawk and Small 1998).

It is only recently that the civil engineering community has begun to adopt this advanced technology. Cantieni (1996) investigated model updating of a concrete arch bridge while Pavic et al. (1998) applied the technique to footbridges and concrete floors. These investigations marked the beginning of the successful application of the model updating technology to civil engineering structures. The application of the model updating technology to even more complex structures like cable-stayed bridges is still a challenge to the investigator.

Model updating procedures can be classified as being one-step procedures (global methods) or iterative (local methods). Global methods directly reconstruct the updated global mass and stiffness matrices from the reference data (measured frequencies and mode shapes). Local methods are based on corrections applied to local physical parameters of the FE model. They have good physical interpretation of the obtained modifications and preserve the symmetry, positive-definiteness and sparseness of the stiffness matrix. Global methods simply deliver an updated matrix that regenerates the response data with no guaranteed preservation of these properties. The effective and most popular local methods for model updating are generally based on the sensitivity analysis.

This paper investigates the dynamic assessment of the Safti Link Bridge, a curved deck, single offset pylon, cable-stayed bridge that is a landmark in Singapore, via sensitivity analysis based FE model updating. The analysis was done 
by using the ANSYS code (SAS 1997) for FEA in conjunction with the FEMtools (DDS 1998), a set of software tools used mainly for model updating in mechanical engineering/aerospace applications. Using even imperfect prototype testing data, the FE model has been modified to reflect the true dynamic behavior of the structure with acceptable accuracy.

\section{Bridge Description}

The Safti Link Bridge shown in Fig. 1 was completed in 1995. World-renowned structural engineers, Professors T.Y.Lin and Philip Chow initiated its conceptual design that was executed by T.Y.Lin SEAsia.

The bridge comprises a curved concrete box deck and a single independent offset pylon. Fig. 2 shows the schematic plan, angled and elevation views of the bridge. The arc of the curved deck along the centerline spans $100 \mathrm{~m}$ between abutments and the total width of the traffic lanes is $8 \mathrm{~m}$ with two $2 \mathrm{~m}$ walkways. The deck has a 180m radius of curvature to the centerline where nine 'bridge stay' cables are attached at $10 \mathrm{~m}$ centers, supporting the deck from the pylon which is held in position by three pairs of 'back stay' cables.

The concrete deck girder comprises a central 2m deep box with 'wing-tip' girder plus 3m of cantilever on each side. Fig. 3 shows the detail of the deck girder. Pre-stressed transverse diaphragms are provided at $5 \mathrm{~m}$ intervals to improve torsional rigidity, to resist transverse bending and to transfer load between the stay cable anchorage and the bridge deck. Loads are also transferred from the deck to the bridge stays by two $0.35 \mathrm{~m}$ thick webs along the center of the girder. 
For greater stability the deck is fixed at the abutments, which rest on a row of $1.4 \mathrm{~m}$ diameter bored piles. A system of $1.25 \mathrm{~m}$ by $1.25 \mathrm{~m}$ ground beams links the back stay anchorage to each other and to the base of the octagonal tapered pylon. Five $1.55 \mathrm{~m}$ diameter bored piles support the pylon footing, while back stay anchorage combine an arrangement of small bored piles and ground anchors. Together with the back stays, the pylon, ground beams and ground anchors form a separated support structure connected to the deck via the bridge stays. The $4^{\text {th }}$ bridge stay (counting from the west side) is vertical, locating its termination in the pylon approximately 30m above its anchorage in the deck, with the pylon continuing to a height $42.55 \mathrm{~m}$ above its base.

All bridge stays were stressed at anchor blocks located in the bridge deck after construction of the deck to progressively lift it clear of the construction supports, while the back stays were stressed from the ground anchor caps.

\section{Dynamic Properties}

Dynamic properties of the bridge were obtained from the FEA conducted using ANSYS and FEMtools and EMA based on prototype testing.

\subsection{FE Modeling}

FEA has for some decades been an accepted tool for simulating structural behavior, but creating a good model is not an easy task. Many different modeling strategies are available: which element types, how many degrees of freedom etc.. These strategies depend on the skill and experience of the analyst and on the intended application of the model, e.g. for predicting behavior due to static, 
dynamic and/or thermal loading. However preparation of a FE model that will be a candidate for updating requires the consideration of additional factors not normally taken into account in conventional FE model construction. Of these, the choice of updating parameters is most important. The inaccuracies or uncertainties in the structure must be expressed as parameters such that these uncertainties can be assessed quantitatively. In addition, when constructing FE models for updating, they have to be exchangeable between the FEA and updating software. In this case study, only element types supported both in the ANSYS and FEMtools were used in generation of the FE model.

Based on the above considerations, the structural components of the box-type deck were modeled by shell elements. The pylon and ground beams were modeled as conventional 3-D beam elements. The shell elements and 3-D beam elements are supported both in ANSYS and FEMtools, so they can be exchanged between both codes, but restrictions to certain element types presented some difficulties.

As a tension structure the cable tensions should have the affect of increasing the stiffness of the deck against transverse (vertical and lateral) vibrations via geometric stiffness effects. Unfortunately, FEMtools cannot process the effects of cable tensions so the cables were each modeled with a single conventional unloaded 3-D beam with low flexural rigidity. Prior analyses had been conducted (Brownjohn et al. 1999) using SAPIV in which it was found that neglecting cable tension resulted in reductions of $2 \%$ and $4 \%$ in first (symmetric) and second (anti-symmetric) vertical bending modes with the reductions of less than $0.5 \%$ for other modes. For the case of a suspension bridge deriving its stiffness from cable tensions, the approximation of ignoring the tensions would be unacceptable but in this case it is 
not unreasonable. In ANSYS the geometric stiffness could be set up in a way that mimics the actual in-situ construction process of the bridge by introducing axial strains in the cables, then running a static analysis to determine an equilibrium state in which the cables are 'pre-stressed'. This state could be used in the free vibration analysis but the strategy could not be incorporated into the automated iterative cycle even when using dynamic exchange of matrices between FEMtools and ANSYS so for tension structures with significant geometric stiffness a different approach would be required. The principle of sensitivity-based model updating can be applied directly in a loop involving manually iterated free-vibration solutions of any FE code that provides for geometric stiffness. This has been done for one suspension bridge (Brownjohn 1997).

For the pylon, it would be more appropriate to use elements (BEAM54) available in ANSYS which can model the varying cross-section, but FEMtools does not support this element type. The geometrical properties were taken as the mean values of those at the nodes of the element for each beam element in the pylon model, introducing a minor error into the analysis which could be accounted for in the updating.

As for the boundary conditions, the foundation restraints and abutment restraints due to the piles are essentially fixed in translation at the support points, while the deck ends were assumed as pinned.

\subsection{Prototype Testing}

A dynamic site test of the bridge was conducted to determine the character of the three-dimensional vibration mode shapes and frequencies up to approximately 
$10 \mathrm{~Hz}$. The pylon was inaccessible so measurements were restricted to the deck and were made in vertical and radial directions at locations $0 \mathrm{E}$ to $10 \mathrm{E}, 0 \mathrm{~W}$ to $10 \mathrm{~W}$ and 4C as shown in Fig. 4. Two techniques were employed: ambient vibration testing (AVT) and forced vibration testing (FVT). A set of eight force balance accelerometers was used with low-pass filtered signals digitally recorded on a portable computer via an A/D converter. A $5.5 \mathrm{~kg}$ instrumented sledgehammer was used for FVT, and breezes, vehicles or pedestrians were relied on for the AVT. The testing is fully described elsewhere (Brownjohn et al. 1999).

\subsection{Correlation Analysis}

In order to correlate the results between initial FEA and EMA, the FE model data generated in the ANSYS and the measured data were imported into the updating software through interface programs. The pairing of FE model nodes and measurement points (circle points) is shown in Fig. 5. The correlation of dynamic properties is listed in Table 1 . The modal assurance criterion (MAC) value is a coefficient analogous to correlation coefficient in statistics or coherence in signal processing. It compares ordinates of mode shapes from FEA and EMA and gives a value of unity for perfect correlation while returning a value of zero for uncorrelated orthogonal modes. It is defined as follows,

$$
\operatorname{MAC}\left(\phi_{\mathrm{a}}, \phi_{\mathrm{e}}\right)=\frac{\left|\phi_{\mathrm{a}}^{\mathrm{T}} \phi_{\mathrm{e}}^{\mathrm{T}}\right|^{2}}{\left(\phi_{\mathrm{a}}^{\mathrm{T}} \phi_{\mathrm{a}}\right)\left(\phi_{\mathrm{e}}^{\mathrm{T}} \phi_{\mathrm{e}}\right)}
$$


where, $\phi_{\mathrm{a}}$ and $\phi_{\mathrm{e}}$ are the analytical and experimental mode shape vectors, respectively. The superscript $\mathrm{T}$ denotes the vector transpose.

Table 1 shows that the correlation was not too good between FEA frequency $f_{F E A}$ and EMA frequency $f_{E M A}$ (except for first bending mode) with differences $D_{f}$ exceeding $10 \%$ and even reaching $40 \%$. The correlation of mode shapes expressed by MAC values seems good except for the $2^{\text {nd }}$ bending mode (MAC value of 63.8\%), although MAC statistics are imperfect indicators of modal correlation that cannot compete with visual comparison. The descriptions given in column 6 in Table 1 are the mode shapes having predominant vertical bending or torsion of the deck girder. Being a complex asymmetric structure vertical, lateral and torsional responses occurred together in each mode to varying degrees. The mode shapes are shown in Fig. 11 in which the EMA ordinates are shown as dots on the FEA modes.

Two other ways of comparing FEA and EMA modes are shown in Fig. 6 and Fig. 7. Fig. 6 shows pairing of frequencies between initial FEA and EMA emphasizing errors as departures from a diagonal line with unit slope. The MAC matrix, which illustrates orthogonality conditions between all combinations of analytical and experimental mode shapes, is shown in Fig. 7. For comparable modes the MAC values are high, while off the diagonal dissimilar modes are indicated by values close to zero.

\section{FE Model Updating}

The initial FEA for the bridge was not 100\% successful in assessment of dynamic properties. Model updating was used to improve the FEA predictions. 


\subsection{Updating Procedures}

In applying FE model updating technology (Brownjohn and Xia 1999), the procedure for model updating contains three aspects: selection of responses as reference data, selection of parameters to update and model tuning. Prior experience shows that a successful updating is strongly dependent on correct selection of responses and on the choice of uncertain model parameters.

The responses include resonant frequencies and mode shapes ordinates that are strongly dissimilar between FEA and EMA. In this case all of the EMA mode shape ordinates and frequencies were selected as responses. The choice of parameters is a crucial step in model updating. The important issues are firstly, how many parameters should be selected, and secondly, which parameters from many candidates are preferred? It generally requires the application of physical and mathematical insight. Physically, the selected parameters must be uncertain in the model. Otherwise, the blindly updated structural components may lose their originally certain properties and produce meaningless results in the updated FE analysis. Mathematically, if the estimation of too many parameters is attempted then the problem may appear ill-conditioned or arbitrary because the observations are limited in a vibration testing. In order to have a well-conditioned updating problem, and bearing in mind the limitation of the measurements, it is necessary to select those updating parameters that will be most effective in producing a genuine improvement in the modeling of the structure. Therefore, the number of updating parameters should be kept small, and such parameters should be chosen with the aims of correcting recognized uncertainty in the model and that the data should be sensitive to them. One good way to assess this is to conduct a sensitivity analysis 
that computes the sensitivity coefficient defined as the rate of change of a particular response quantity with respect to a change in a structural parameter. Structural parameters having consistent large values are chosen. For all selected responses and parameters, the sensitivity matrix [S] is obtained as follows,

$$
[S]_{i j}=\frac{\partial R_{i}}{\partial P_{j}}
$$

where, $R_{i}$ and $P_{j}$ represent a structural response and parameter, respectively. The subscripts are $\mathrm{i}=1 \ldots \mathrm{N}$ for $\mathrm{N}$ responses and $\mathrm{j}=1 \ldots \mathrm{M}$ for $\mathrm{M}$ parameters. Equation (2) is a differential analysis for sensitivity coefficient. The sensitivity matrix can be computed for all physical element properties (material, geometrical and boundary etc.) by using direct derivation or perturbation techniques depending on whether or not mass and stiffness are proportional to the property.

When sensitivity analysis is used to help selection of parameters for model tuning, one should start with all possible parameters, then identify sensitive and insensitive areas and then eliminate ineffective (low sensitivity) parameters. The effective parameters (high sensitivity) can be further examined by the application to arrive at a selection suitable for model tuning. The uncertain parameters in the bridge structure may include the Young's modulus $E$ and mass density $\rho$ of the reinforced concrete components, cross-sectional area $A_{x}$ and inertia moment $I$ of the beam structures such as pylon, the thickness $H$ of shell components of the deck girder and the boundary fixities. Out of the possible total of 138 structural parameters, only 21 of these shown to have stronger influence on responses were 
chosen and are listed in Table 3. The envelope of normalized sensitivities of responses to the selected parameters is shown in Fig. 8.

In spite of low sensitivity values for parameter Young's modulus $E$ of walkway deck (parameter 1), and mass density $\rho$ of web and lower central deck (parameter 12), these two parameters were still selected because they apply to the major structural components. Also note that the parameters of the pylon were included even though pylon response was not measured, since the pylon participates in most of the deck vibration modes.

Although the fixities of the piled foundations and deck end bearings were apparently very uncertain it turned out that the sensitivities of the responses to the boundary parameters were close to zero. Pinned deck bearings and fully fixed piles were used and boundary conditions were not chosen as structural parameters.

After selection of responses and parameters, an iterative procedure for model tuning was conducted. The selected parameters were estimated during an iterative process in the tuning procedure. A tuning procedure was finished when a given difference margin (tolerance) was achieved or an allowed number of iterations was completed. In the formulation of parameter estimation, based on the penalty function method, the true responses or experimental responses were expressed as functions of analytical responses, structural parameters and the sensitivity coefficient matrix in terms of a truncated Taylor series expansion limited to the linear term as follows,

$$
\left\{\mathrm{R}_{\mathrm{e}}\right\}=\left\{\mathrm{R}_{\mathrm{a}}\right\}+[\mathrm{S}]\left(\left\{\mathrm{P}_{\mathrm{u}}\right\}-\left\{\mathrm{P}_{0}\right\}\right)
$$

or 


$$
\{\Delta \mathrm{R}\}=[\mathrm{S}]\{\Delta \mathrm{P}\}
$$

where $\{\Delta R\}$ is the difference between $\left\{R_{e}\right\}$, the vector of experimental response values and $\left\{\mathrm{R}_{\mathrm{a}}\right\}$, the vector of analytical response values; $\{\Delta \mathrm{P}\}$ is the difference between $\left\{\mathrm{P}_{\mathrm{u}}\right\}$, the vector of updated parameter values and $\left\{\mathrm{P}_{0}\right\}$, the vector of current parameter values. [S] is the sensitivity matrix that can be obtained from the equation (2). The sensitivity matrix [S] is usually a rectangular matrix $(\mathrm{N} \neq \mathrm{M})$. Equation (4) may be determined, over-determined or under-determined depending on the fact that the number of responses is equal to, larger than or smaller than the number of parameters, respectively. In any case, the estimation of $\{\Delta \mathrm{P}\}$ in the equation (4) can be solved using the pseudo-inverse technique or Bayesian estimation technique. Since the Taylor's expansion is truncated after the first term, the neglected higher order terms necessitate several iterations, especially when $\{\Delta \mathrm{R}\}$ contains large values. It should be noted that when too large discrepancies exist between the experimental and analytical models, the validity of the Taylor series truncations in equation (3) is undermined and iterative process is prone to divergence. Usually it is required that a reasonable approximation is obtained by manual methods i.e. engineering judgement before updating automatically, but Lin at. al. (1995) proposed a modification to the modal sensitivity method that enables convergence for larger magnitudes of FE modeling errors.

Although the tuning procedure is an automatic process, it is still not a black box and requires e.g. correct choice of tuning parameters and reference responses to get the best results. During running an exercise, it is impossible to get a desirable result after only one or two tuning procedures and it is necessary to adjust frequently the 
tuning strategies for a successful updating. For example, if a satisfactory result can not be obtained after a tuning procedure, a continuous tuning procedure can start again taking only some of responses or some of parameters, or changing the convergence margin or maximum number of iterations.

In order to avoid physically impossible updated parameter values, the lower and upper bounds for the parameter values should be applied. If a parameter value reaches its allowable extreme during iterative model tuning, then the parameter becomes ineffective during the rest of the procedure. The bound levels of parameters should be set lower in every tuning procedure so as to guarantee the accumulated bound levels not to exceed the allowable extreme after finishing the final tuning procedure. It is possible that convergence can not be obtained to a satisfactory degree when parameter bounds are defined. A trade-off between physically acceptable parameter values and convergence level is then required.

\subsection{Updated Results}

Table 2 lists the correlation values after updating. It can been seen that the differences $D_{f}$ between FEA frequency $f_{F E A}$ and EMA frequency $f_{E M A}$ were all reduced to below $10 \%$. The correlation of mode shapes was also improved since MAC values all exceeded $90 \%$, with the exception to the $4^{\text {th }}$ bending mode shape. The worst MAC value is $84.7 \%$. Even though this sounds high, value MAC values should be used with caution since they can mask some significant variations in the

mode 'shape'. For the $2^{\text {nd }}$ bending mode MAC value has increased from $63.8 \%$ to 96.3\%. The good pairing of frequencies between updated FEA and EMA is shown 
in Fig. 9; all paired points are close to the diagonal. Inspection of the MAC matrix (Fig. 10) shows an improvement on the prior FE model, Fig. 7.

Table 3 lists the changes $\Delta_{\mathrm{p}}$ in value of the selected parameters with initial value $\mathrm{V}_{\mathrm{I}}$ and updated value $\mathrm{V}_{\mathrm{U}}$. The initial values of parameters in the table were the design values of parameters. For the reinforced concrete the design values were quite different from actual updated values. Theoretically, it is very difficult to determine accurately the values of these physical properties. Although it is possible to place limits on the allowable ranges of the chosen structural parameters, the final results should be checked against normal practice. In this case the updated values of the Young's modulus $E$ and the mass density $\rho$ of the concrete components were within the ranges given by the British Code of Practice for the Structural Use of Concrete and the American Concrete Institute Building Code according to Neville (1982).

The mode shapes of dominant vibration from updated FEA are compared with EMA in Fig. 11. In order to visualize clearly, the FE model is shown only as a wire and the lower components such as the web, lower central deck and lower deck of the deck girder were selected out. The circle points in Fig. 11 represented the EMA mode shapes. Visual checking shows satisfactory agreement.

In order to check the reliability of the updated model, an exercise was done by rerunning the updated numerical model with perturbed parameters about values of the updated parameters to generate a perturbed model, taking the frequencies and mode shapes as reference data, and performing an updating procedure for the perturbed model. It was found that the perturbed model converged very fast to the updated mode only after 5 iterations. The maximum difference of the frequency was 
only $0.15 \%$ and the minimum MAC value arrived at $99.8 \%$ after the updating procedure. The exercise verified the success of the updating procedure with experimental data.

\section{Discussion}

The FE model updating technology has been applied successfully in the dynamic assessment of the cable-stayed bridge. It is important to emphasize here what is learnt from this exercise since it is likely that the process will increase in popularity.

\subsection{FE Modeling for Updating}

There are some particular considerations when modeling a structure as a candidate for FE model updating. The initial FE model used in this study was not the first attempt at modeling the bridge. A previous FE model adapted from one used by the designer for checking static load combinations was initially chosen and adapted as a candidate for updating. This model featured a 'spine beam' by using conventional 3-D beam elements to represent the deck girder (Brownjohn et al. 1999 and Xia 1999). These beam elements incorporated all the bending, torsional and inertial properties of the box-deck while low density elements capable of transferring static loads but not representing inertia properties were used for the deck.

Updating was applied to this model but the results were not ideal, having maximum frequency error of $15 \%$. Even to achieve this level of agreement, six selected parameters changed by $100 \%$, losing physical relevance for the structure. 
By condensing deck properties into a spine beam model the original geometrical properties of the 'wing-tip' box deck were lost. The lesson here is that the level of detail has to be high if the physical properties are to remain in reasonable ranges.

\subsection{Model of Cables}

As mentioned the stressing in the cables was not modeled and single conventional 3-D beam elements were used for each stay cable. For all but the lowest two vibration modes this simplification has negligible effect on the results. There is no need to model the cables with multiple elements unless the cable dynamics themselves are an issue. Separate analyses with ANSYS showed that using multiple elements leads to a proliferation of modes featuring cable vibrations and little else.

Despite the simplification the updating produced good results. There remains a consistent underestimation of modal frequencies and it is tempting to reconcile this with the underestimation due to neglecting geometric stiffness, except that the distribution of frequency errors is not biased to the lower modes.

The lesson here is that such provided the dynamics of the stay cables themselves are not relevant, a reasonable approximation can be obtained with equivalent springs.

\subsection{Interpretation of Parameter Changes}

The selected parameters included the physical properties such as Young's modulus $E$ and mass density $\rho$ and the geometrical properties such as crosssectional area $A_{x}$ and thickness $H$ of the structural components. The changes in these parameters represented the global changes of stiffness and mass leading to 
global changes of dynamic properties of the bridge structure. The changes in selected parameters have a random appearance because some increase while others decrease but close inspection shows that the changes in the parameters accord with the changes in dynamic behavior of the updated FE model. Except for mode 1, all the frequencies increased, consistent with a global increase in stiffness; Table 3 shows increases in Young's modulus $E$ and thickness $H$ of traffic deck, lower deck and parapet wall while mass density $\rho$ of traffic deck and parapet wall were reduced. The traffic deck and lower deck are thin-walled closed boxes dominating the bending and rotational stiffness properties of the ‘wing-tip’ deck.

Of course, the changes in selected parameters must also meet the requirement of mode shapes closing to EMA values. From this point of view, it should be difficult to interpret the changes in the parameters. However, it could be realized that all updated values of selected parameters represented their actual values for closing the model to reality.

\subsection{Effect of Quality of Testing Data on Updating}

Since updating is based on the assumption that test data are correct the reliable updating depends on the accuracy of the test data. It also depends on the quality of the test data (Mottershead and Friswell 1993) and this case study illustrates this. The MAC value for the $4^{\text {th }}$ bending mode (before updating) was $84.7 \%$, low compared to values for other modes, due to the less reliable data for the higher mode. Modal data for higher modes are not so accurate both experimentally and analytically, partly due to spatial resolution of mode shapes, and updating does not work so well for these modes. The effect is also visible for $3^{\text {rd }}$ bending, $3^{\text {rd }}$ torsion and $2^{\text {nd }}$ torsion 
modes having lower MAC values compared to $1^{\text {st }}$ bending, $2^{\text {nd }}$ bending and $1^{\text {st }}$ torsion (around 91\% against 97\%). Apparently quality of test data is more critical for identifying and updating the higher modes.

As well as specific effects on higher modes, test data quality will also be affected by the ambient effects e.g. wind, traffic and temperature. In fact the vibration sources used in AVT also contaminate the signal with noise. This represents a major problem with the largest civil engineering structures, which require impractical force inputs to match signal/noise ratios that are acceptable in laboratory testing. When using AVT methods the response peak in the frequency domain is reduced and slightly flattened by noise, distorting the mode shape. Problems of bias, resolution, noise and averaging are acute for large structures with low frequencies, non-stationary inputs and (often) inhospitable conditions. Moreover for AVT, the measured mode shape is usually an 'operating deflected shape' containing contributions from other modes which will only be negligible if modes are well separated.

Little can be done to improve noisy data even if the noise level can be measured; the best that can be done is to define confidence bands relating to noise levels. To protect the investment of time and money in testing, the best equipment and greatest care in selection of transducer locations and signal ranges are required. To that end a prior dynamic analysis is usually required.

\section{Conclusions}

1. The dynamic properties obtained by the FEA for the complex structures like the Stafi Link Bridge are not always consistent with the measured results due to the 
modeling errors and the uncertainties in the structure. It is necessary to improve the FE model for successful dynamic assessment of the structure.

2. The model updating is a feasible and effective technology for improvement of the FE model by modification of the parameters with uncertainties existing in the structure, based on the prototype testing data. The successful application of the model updating technology to the dynamic assessment of the Safti Link Bridge represented a crucial step toward using the technology for dynamic assessment of complex structures in civil structural engineering.

3. The appropriate FE modeling of a structure is the key to successful updating. The structure should be modeled with as much detail as possible so as to represent geometric and structural form.

4. Using a conventional unloaded 3-D beam element to model a tensioned cable in the cable-stayed bridge can still produce good results in analysis of dynamic properties.

5. There is still much to learn about FEM updating. For example the methods for arriving at a starting point close enough to the solution to allow convergence are not formalised. Also updating places special requirements on modal test strategy and it is recognised that some form of dynamic analysis should precede a modal test to aid in selecting the correct transducer locations and frequency range for capturing the modes that contribute the most to the updating. The optimisation also extends to selection of the appropriate type and number of structural parameters in relation to the responses. Guidelines for these steps will evolve through further studies on civil structures. 
Table 1. Correlation between Initial FEA and EMA

\begin{tabular}{|c|c|c|c|c|l|}
\hline No & $\mathrm{f}_{\mathrm{FEA}}(\mathrm{Hz})$ & $\mathrm{f}_{\mathrm{EMA}}(\mathrm{Hz})$ & $\mathrm{D}_{\mathrm{f}}(\%)$ & $\mathrm{MAC}(\%)$ & \multicolumn{1}{|c|}{ Mode Shape } \\
\hline 1 & 1.26 & 1.18 & 6.39 & 96.5 & $1^{\text {st }}$ Bending \\
\hline 2 & 1.61 & 2.76 & -41.58 & 63.8 & $2^{\text {nd }}$ Bending \\
\hline 3 & 2.62 & 3.59 & -27.09 & 96.4 & $1^{\text {st }}$ Torsion \\
\hline 4 & 3.71 & 4.61 & -19.50 & 87.6 & $3^{\text {rd }}$ Bending \\
\hline 5 & 4.88 & 6.10 & -19.96 & 97.8 & $2^{\text {nd }}$ Torsion \\
\hline 6 & 6.16 & 7.00 & -11.94 & 86.5 & $4^{\text {th }}$ Bending \\
\hline 7 & 7.00 & 9.10 & -23.11 & 94.6 & $3^{\text {rd }}$ Torsion \\
\hline
\end{tabular}


Table 2. Correlation between Updated FEA and EMA

\begin{tabular}{|c|c|c|c|c|l|}
\hline No & $\mathrm{f}_{\mathrm{FEA}}(\mathrm{Hz})$ & $\mathrm{f}_{\mathrm{EMA}}(\mathrm{Hz})$ & $\mathrm{D}_{\mathrm{f}}(\%)$ & $\mathrm{MAC}(\%)$ & \multicolumn{1}{|c|}{ Mode Shape } \\
\hline 1 & 1.14 & 1.18 & -3.67 & 97.8 & $1^{\text {st }}$ Bending \\
\hline 2 & 2.62 & 2.76 & -4.89 & 96.3 & $2^{\text {nd }}$ Bending \\
\hline 3 & 3.29 & 3.59 & -8.36 & 97.1 & $1^{\text {st }}$ Torsion \\
\hline 4 & 4.18 & 4.61 & -9.36 & 90.8 & $3^{\text {rd }}$ Bending \\
\hline 5 & 5.86 & 6.10 & -4.00 & 91.9 & $2^{\text {nd }}$ Torsion \\
\hline 6 & 6.60 & 7.00 & -5.70 & 84.7 & $4^{\text {th }}$ Bending \\
\hline 7 & 8.70 & 9.10 & -4.38 & 91.4 & $3^{\text {rd }}$ Torsion \\
\hline
\end{tabular}


Table 3. Changes in Selected Parameters

\begin{tabular}{|c|c|c|c|c|l|}
\hline No & Type & $\mathrm{V}_{\mathrm{I}}$ & $\mathrm{V}_{\mathrm{U}}$ & $\Delta_{\mathrm{p}}(\%)$ & Structural Component \\
\hline 1 & $E$ & $31 \mathrm{GPa}$ & $28.0 \mathrm{GPa}$ & -9.68 & Walkway deck \\
\hline 2 & $E$ & $31 \mathrm{GPa}$ & $25.5 \mathrm{GPa}$ & -17.74 & Upper central deck \\
\hline 3 & $E$ & $31 \mathrm{GPa}$ & $37.0 \mathrm{GPa}$ & 19.35 & Traffic deck \\
\hline 4 & $E$ & $35 \mathrm{GPa}$ & $36.1 \mathrm{GPa}$ & 3.14 & Pylon \\
\hline 5 & $E$ & $31 \mathrm{GPa}$ & $27.5 \mathrm{GPa}$ & -11.29 & Web and lower central deck \\
\hline 6 & $E$ & $31 \mathrm{GPa}$ & $32.4 \mathrm{GPa}$ & 4.52 & Lower deck \\
\hline 7 & $E$ & $31 \mathrm{GPa}$ & $33.4 \mathrm{GPa}$ & 7.74 & Parapet wall \\
\hline 8 & $\rho$ & $2400 \mathrm{~kg} / \mathrm{m}^{3}$ & $1740 \mathrm{~kg} / \mathrm{m}^{3}$ & -27.50 & Parts of pylon linking cables \\
\hline 9 & $\rho$ & $2400 \mathrm{~kg} / \mathrm{m}^{3}$ & $1960 \mathrm{~kg} / \mathrm{m}^{3}$ & -18.33 & Walkway deck \\
\hline 10 & $\rho$ & $2400 \mathrm{~kg} / \mathrm{m}^{3}$ & $2180 \mathrm{~kg} / \mathrm{m}^{3}$ & -9.17 & Traffic deck \\
\hline 11 & $\rho$ & $2400 \mathrm{~kg} / \mathrm{m}^{3}$ & $2210 \mathrm{~kg} / \mathrm{m}^{3}$ & -7.92 & Pylon \\
\hline 12 & $\rho$ & $2400 \mathrm{~kg} / \mathrm{m}^{3}$ & $3150 \mathrm{~kg} / \mathrm{m}^{3}$ & 31.25 & Web and lower central deck \\
\hline 13 & $\rho$ & $2400 \mathrm{~kg} / \mathrm{m}^{3}$ & $3110 \mathrm{~kg} / \mathrm{m}^{3}$ & 29.58 & Lower deck \\
\hline 14 & $\rho$ & $2400 \mathrm{~kg} / \mathrm{m}^{3}$ & $1840 \mathrm{~kg} / \mathrm{m}^{3}$ & -23.33 & Parapet wall \\
\hline 15 & $A_{x}$ & $4.85 \mathrm{~m}$ & $3.5 \mathrm{~m}$ & -27.84 & Parts of pylon linking cables \\
\hline 16 & $H$ & $0.2 \mathrm{~m}$ & $0.15 \mathrm{~m}$ & -25.0 & Walkway deck \\
\hline 17 & $H$ & $0.2 \mathrm{~m}$ & $0.19 \mathrm{~m}$ & -5.0 & Upper central deck \\
\hline 18 & $H$ & $0.2 \mathrm{~m}$ & $0.25 \mathrm{~m}$ & 25.0 & Traffic deck \\
\hline 19 & $H$ & $0.35 \mathrm{~m}$ & $0.28 \mathrm{~m}$ & -20.0 & Web and lower central deck \\
\hline 20 & $H$ & $0.15 \mathrm{~m}$ & $0.18 \mathrm{~m}$ & 20.0 & Lower deck \\
\hline 21 & $H$ & $0.4 \mathrm{~m}$ & $0.55 \mathrm{~m}$ & 37.5 & Parapet wall \\
\hline
\end{tabular}




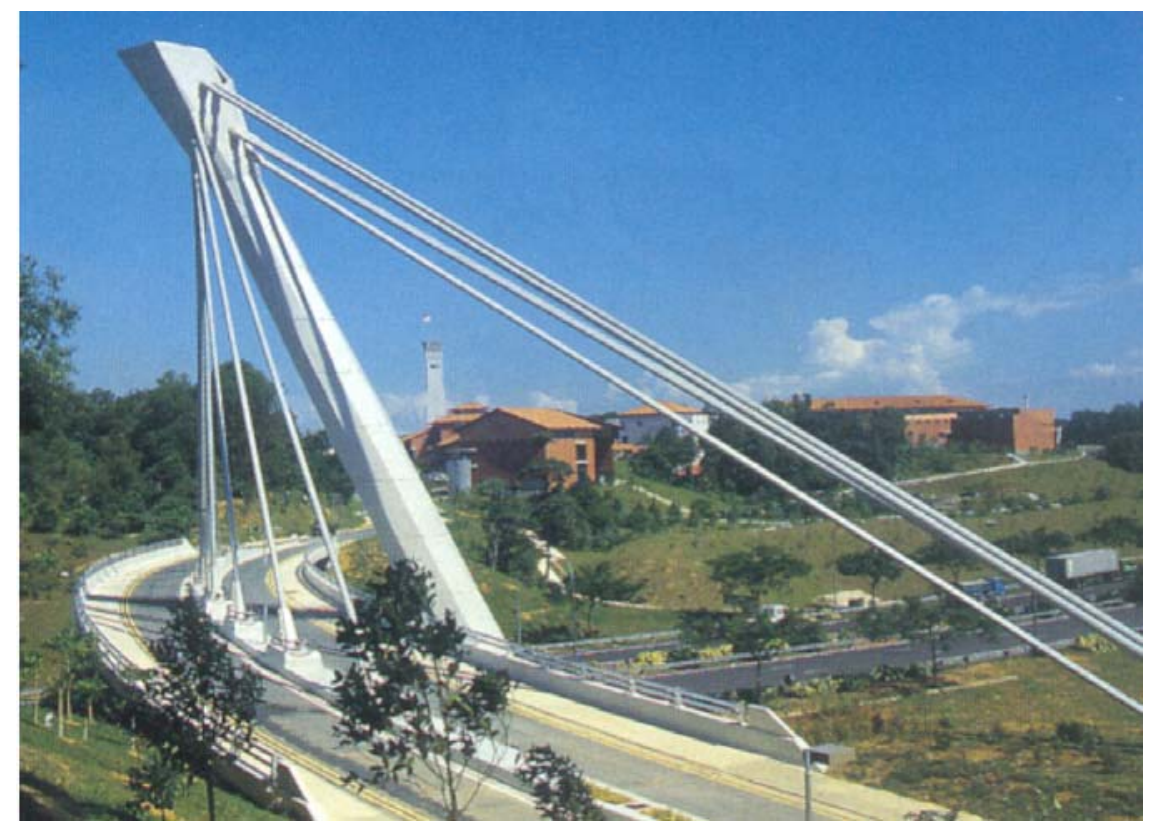

Fig. 1. Safti Link Bridge 


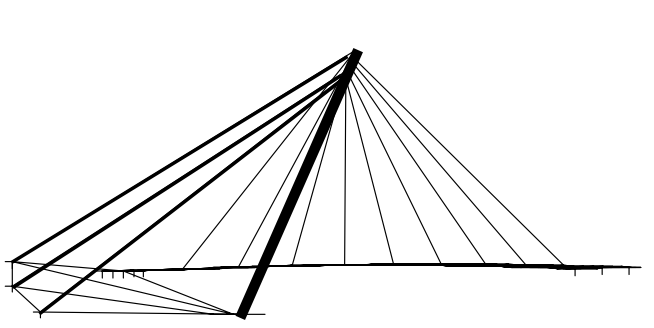

\section{West}

Abutment

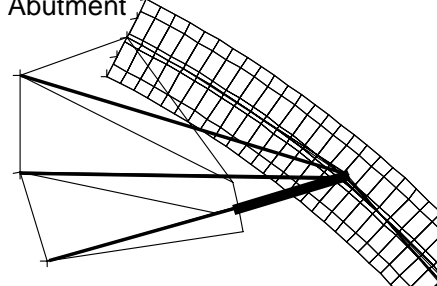

Elevation

Plan View

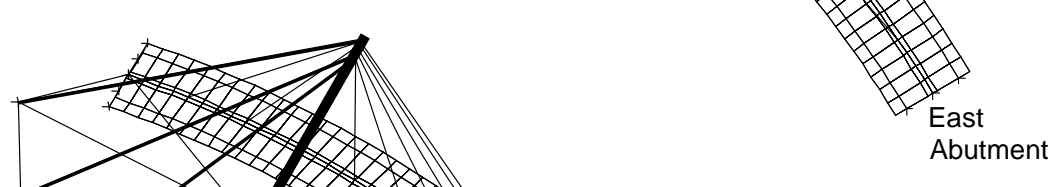

Angled View

Fig. 2. Schematic Views of Safti Link Bridge 


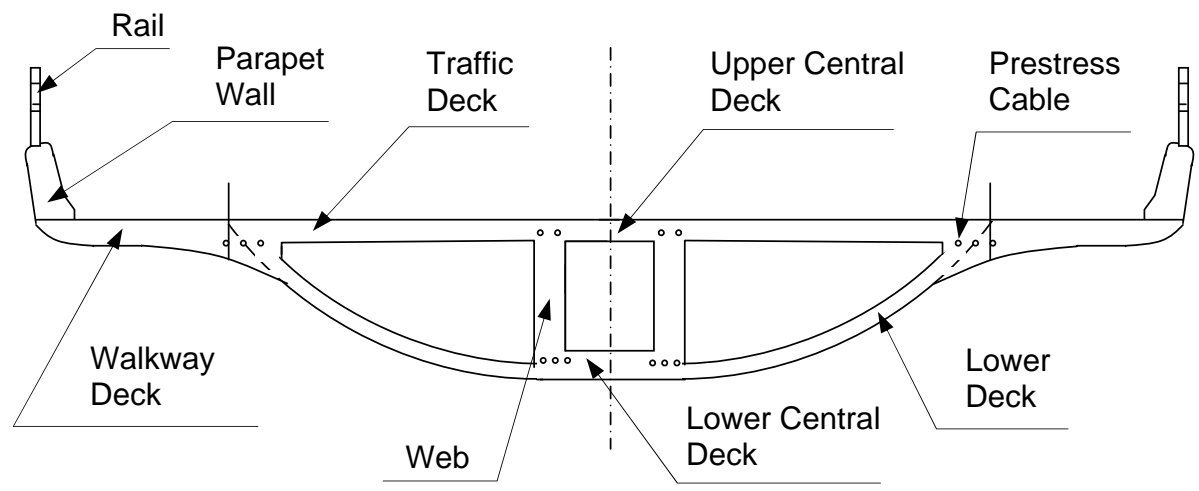

Fig. 3. Detail of Deck Girder 


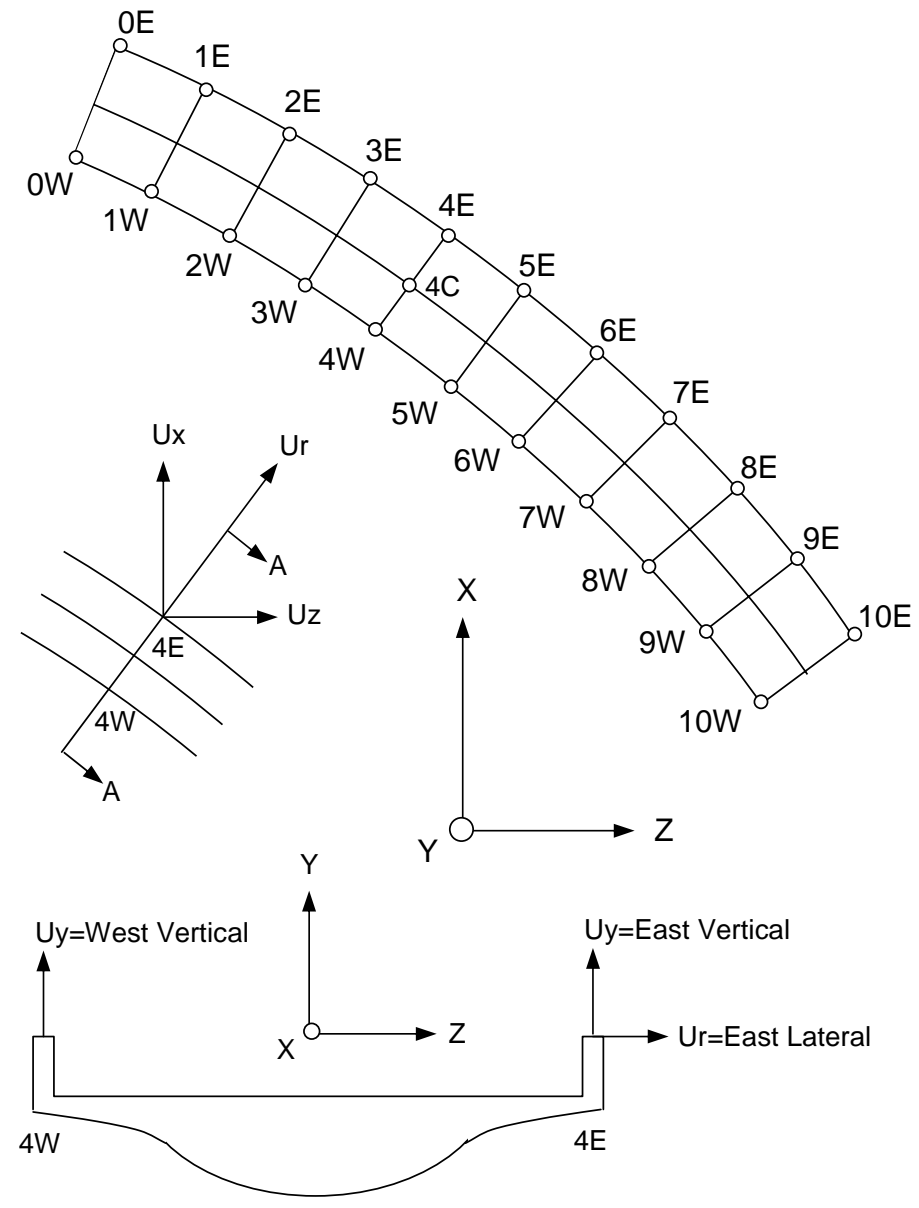

Section A - A

Fig. 4. Detail of Measurement Points 


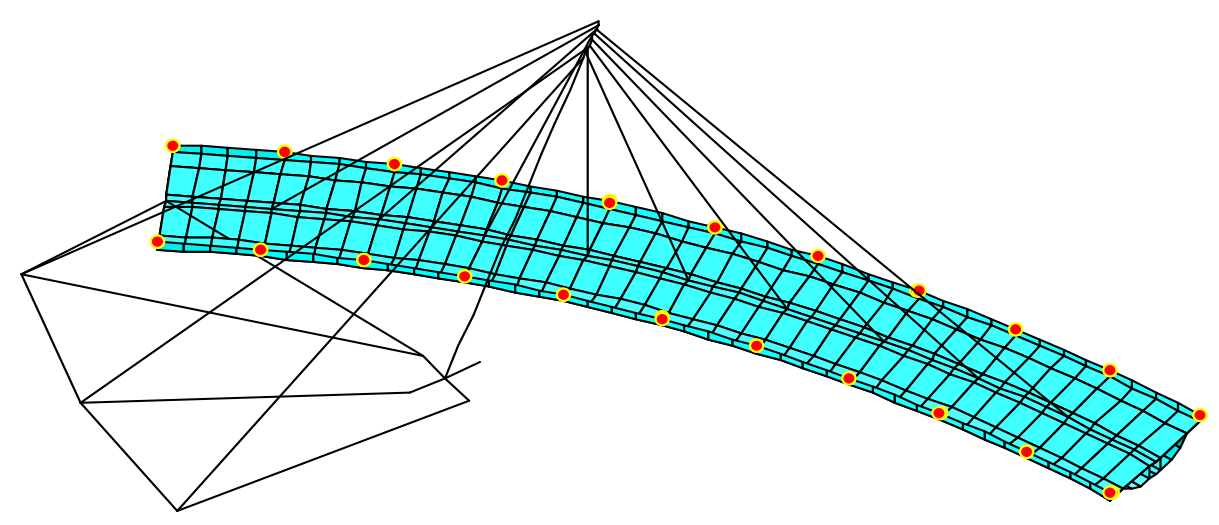

Fig. 5. Pair of FE Model Nodes and Measurement Points 


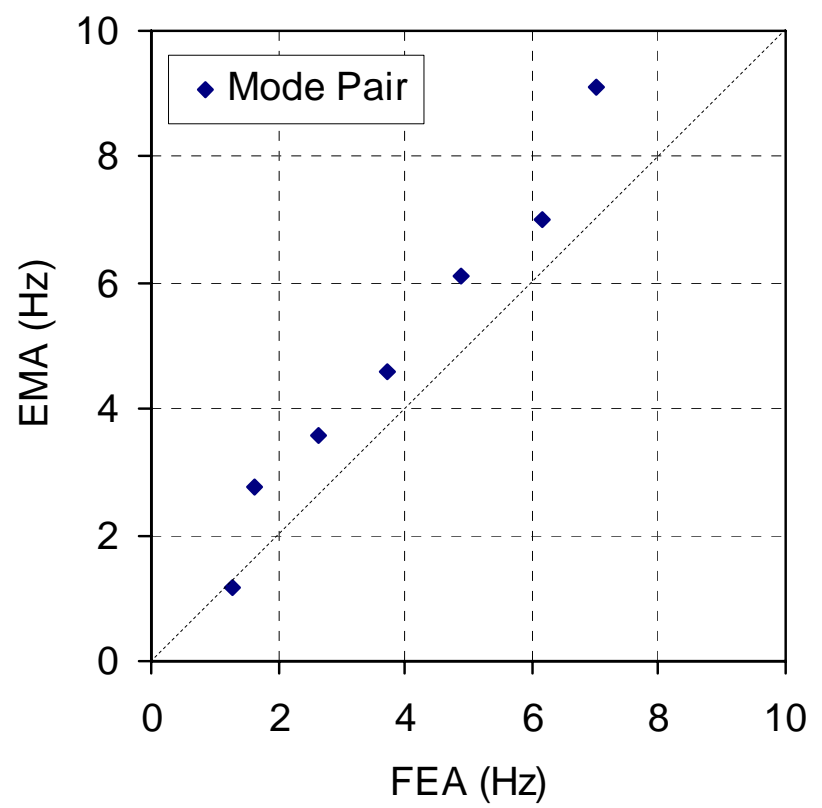

Fig. 6. Pair of Frequencies between Initial FEA and EMA 


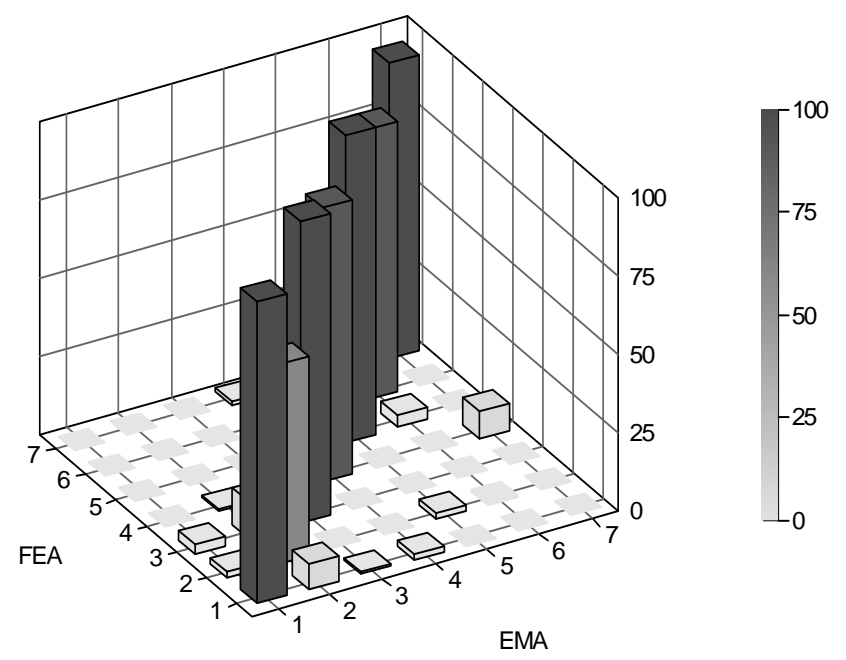

Fig. 7. MAC Matrix between Initial FEA and EMA 


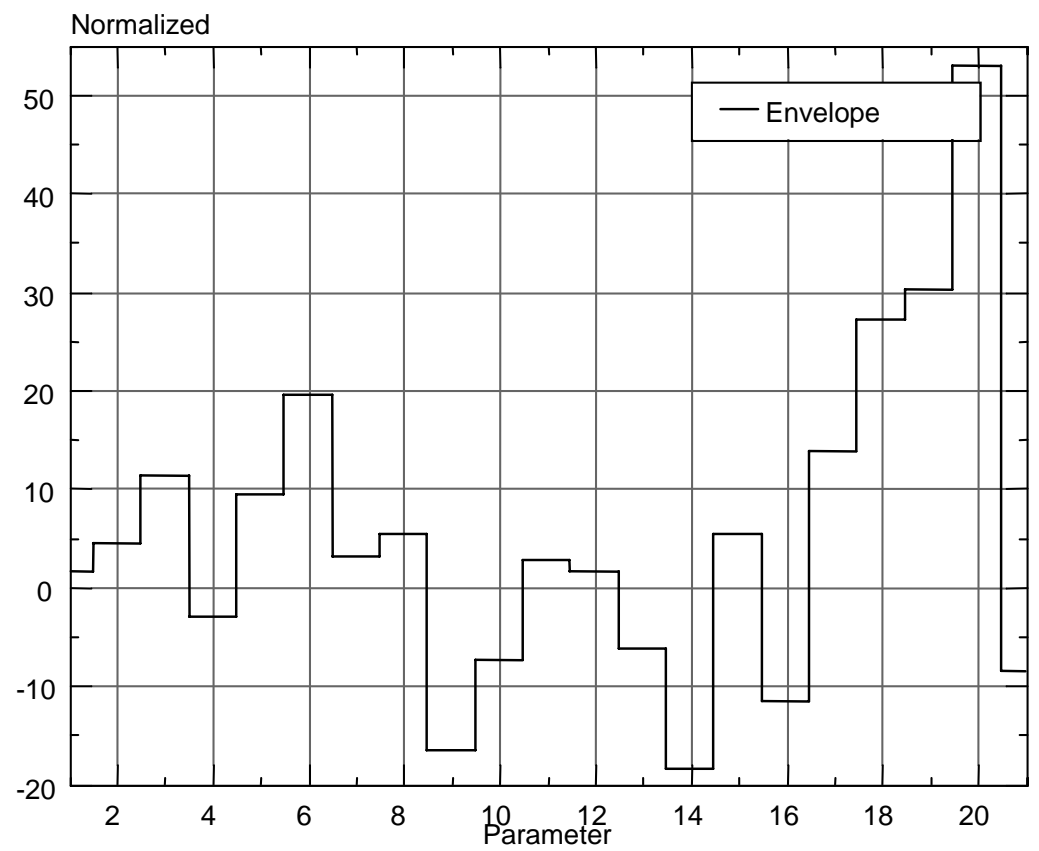

Fig. 8. Envelope of Sensitivity of Responses to Parameters 


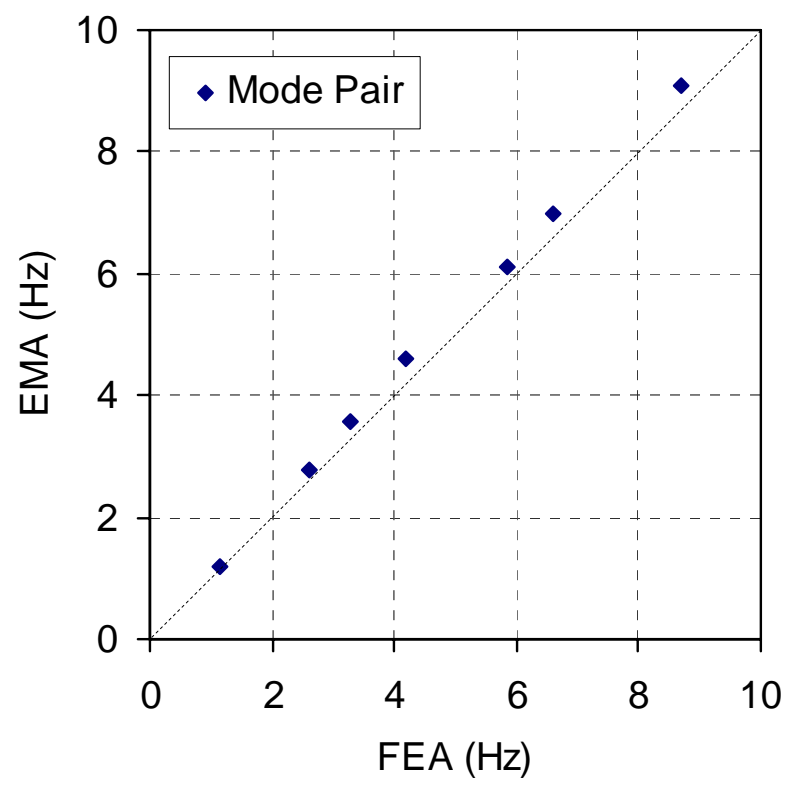

Fig. 9. Pair of Frequencies between Updated FEA and EMA 


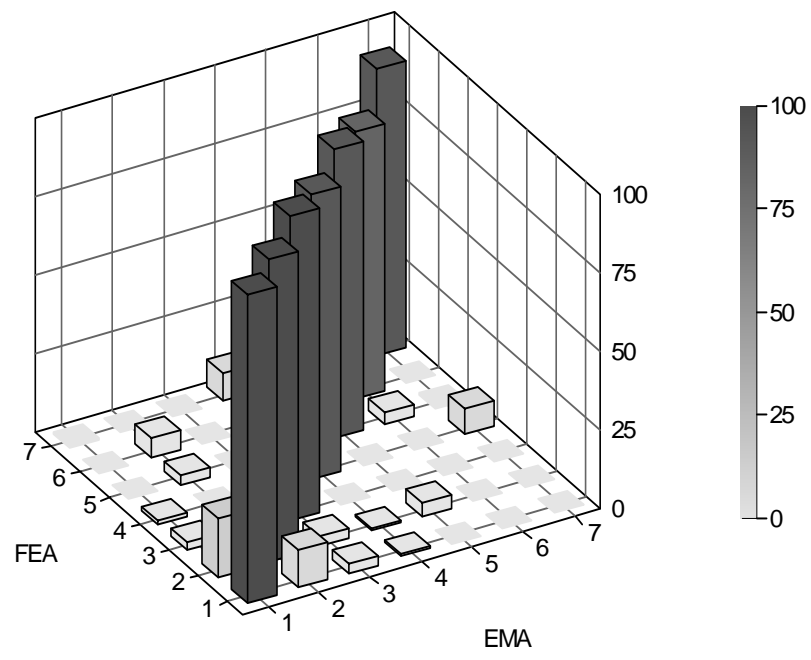

Fig. 10. MAC Matrix between Update FEA and EMA 


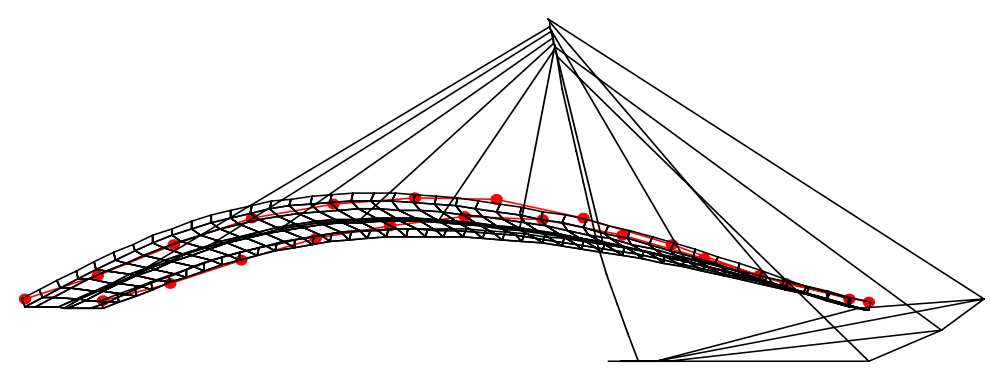

$1^{\text {st }}$ Bending Mode Shape

(a)

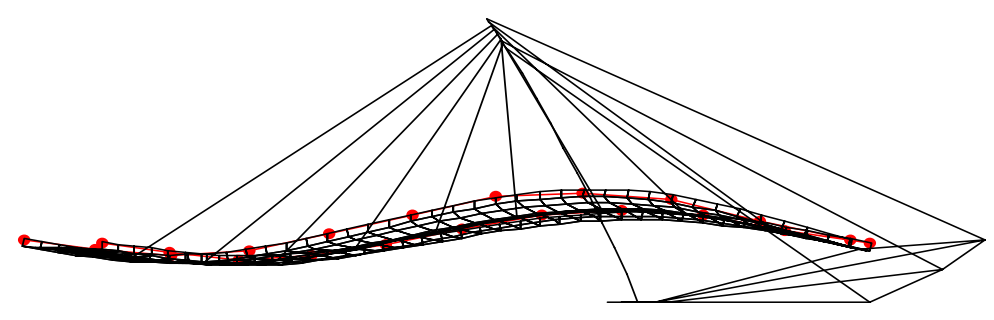

$2^{\text {nd }}$ Bending Mode Shape

(b)

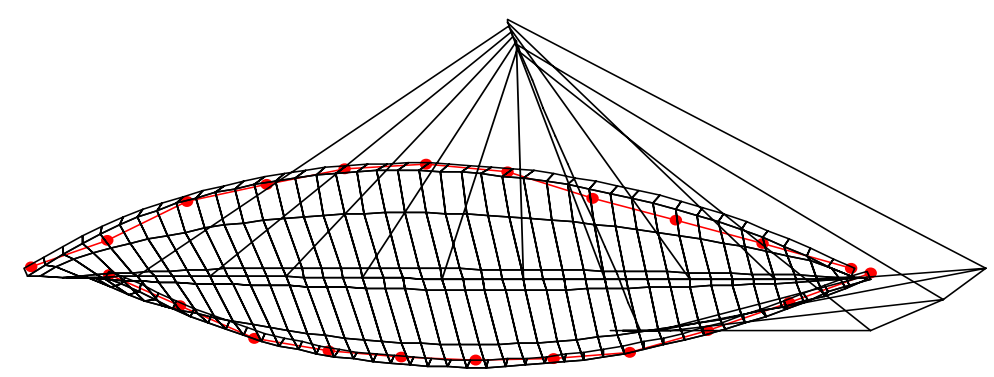

$1^{\text {st }}$ Torsional Mode Shape

(c)

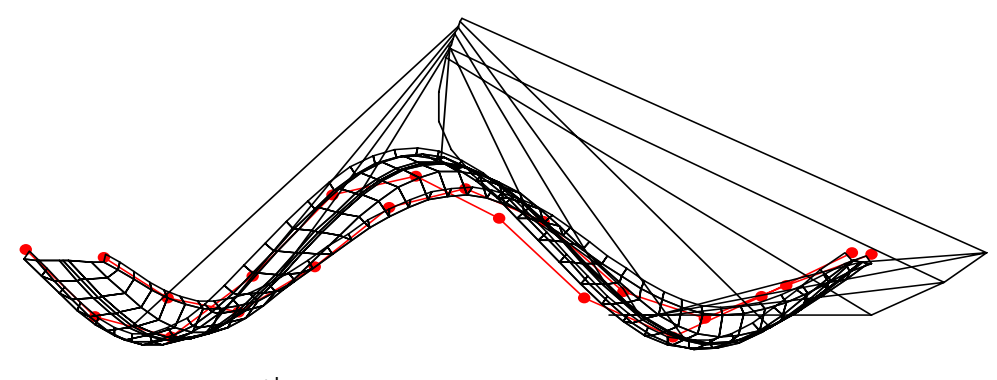

$3^{\text {rd }}$ Bending Mode Shape

(d) 


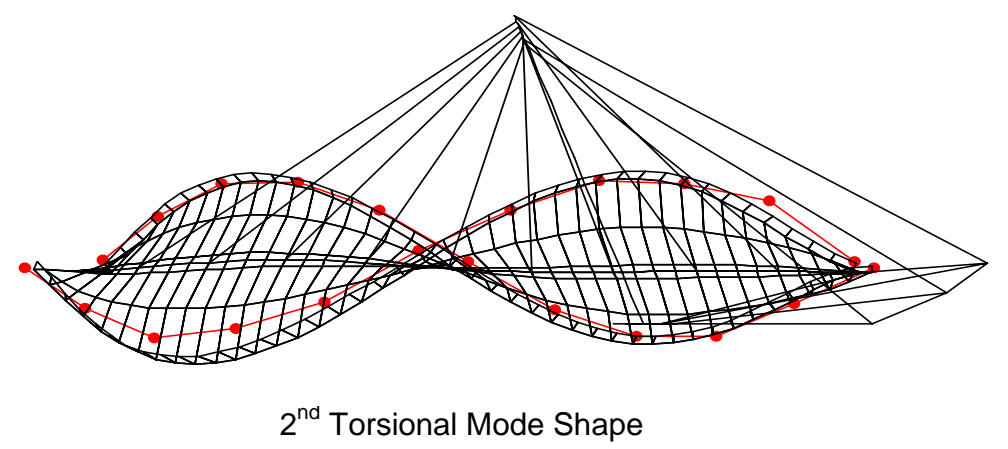

(e)

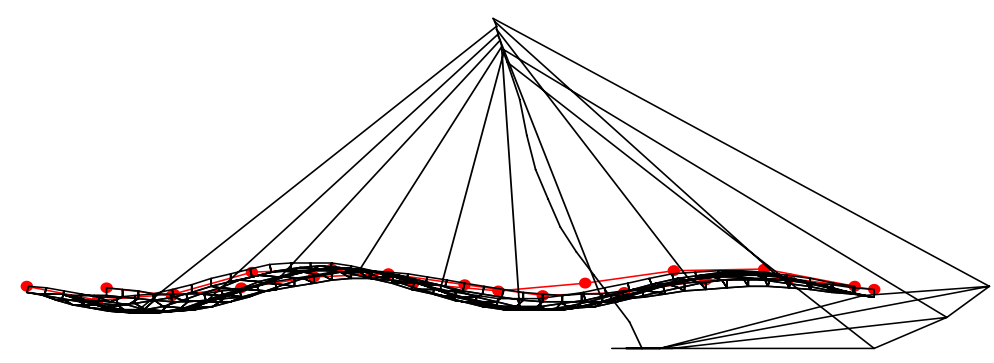

$4^{\text {th }}$ Bending Mode Shape

(f)

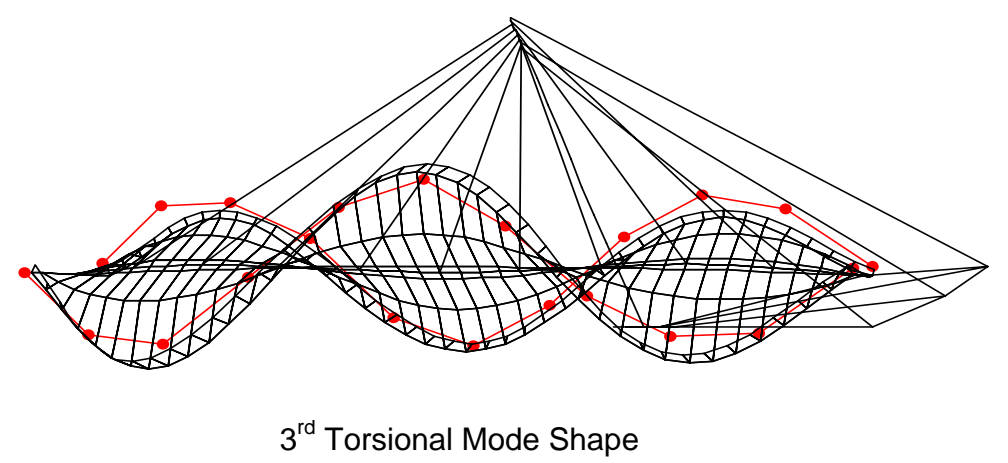

(g)

Fig. 11. Mode Shapes of Dominant Vibration of Deck Girder:

(a) $1^{\text {st }}$ Bending Mode Shape; (b) $2^{\text {nd }}$ Bending Mode Shape;

(c) $1^{\text {st }}$ Torsional Mode Shape; (d) $3^{\text {rd }}$ Bending Mode Shape;

(e) $2^{\text {nd }}$ Torsional Mode Shape; (f) $4^{\text {th }}$ Bending Mode Shape;

(g) $3^{\text {rd }}$ Torsional Mode Shape 


\section{References}

Brownjohn, J. M. W. (1997). "Vibration characteristics of a suspension footbridge.” Journal of Sound and Vibration, Academic Press, 202(1), 29-46.

Brownjohn, J. M. W., Dumanoglu, A. A., and Severn, R. T. (1992). “Ambient vibration survey of the Fatih Sultan Mehmet (Second Bosporus) suspension bridge.” Earthquake Engineering and Structural Dynamics, John Wiley \& Sons, Ltd., 21, 907-924.

Brownjohn, J. M. W., Lee, J., and Cheong, B. (1999). “Dynamic performance of a curved cable-stayed bridge.” Engineering Structures, Elsevier Science Ltd, 21(11), 1015-1027.

Brownjohn, J. M. W., and Xia, P. Q. (1999). "Finite element model updating of a damaged structure." Proceedings of the $17^{\text {th }}$ International Modal Analysis Conference, Kissimmee, Florida, 1, 457-462.

Cantieni, R. (1996). "Updating of analytical models of existing large structures based on modal testing.” Proceedings of the Workshop US-Europe on Bridge Engineering: Evaluation, Management and Repair, Barcelona, Spanish, 1517.

Casa, J. R. (1995). "Full scale dynamic testing of the Alamillo Cable-Stayed Bridge in Sevilla (Spain).” Earthquake Engineering and Structural Dynamics, John Wiley \& Sons, Ltd., 24(1), 35-51.

DDS. (1998). FEMTools User's Manual, Version 1.4. Dynamic Design Solutions, Belgium 
Doebling, S. W., Farrar, C. R., and Prime, M. B. (1998). “A summary review of vibration-based damage identification methods." The Shock and Vibration Digest, Sage Science Press, 30(2), 9-105.

Dumanoglu, A. A., Brownjohn, J. M. W., and Severn, R. T. (1991). "Seismic analysis of the Fatih Sultan Mehmet (Second Bosporus) suspension bridge.” Earthquake Engineering and Structural Dynamics, John Wiley \& Sons, Ltd., 21, 881-906.

Felber, A. J. (1995). “Seismic assessment of existing bridges: one role for dynamic testing.” Proceedings of Bridges into $21^{\text {st }}$ Century, Hong Kong, 765-772.

Felber, A., and Cantieni, R. (1996). “Advances in ambient vibration testing: Ganter Bridge, Switzerland.” Structural Engineering International, IABSE, 6(3), 187190.

Hawk, H., and Small, E. P. (1998). “The BRIDGEIT bridge management system.” Structural Engineering International, IABSE, 8(4), 309-314.

Hearn, G. (1998). “Condition data and bridge management system.” Structural Engineering International, IABSE, 8(3), 221-225.

Kominek, M. (1998). “The Marian Bridge, Czech Republic.” Structural Engineering International, IABSE, 8(4), 283-284.

Law, S. S., and Ko, J. M. (1995). “Ambient vibration measurements of the Tsing Ma Bridge towers.” Proceedings of Bridges into the $21^{\text {st }}$ Century, Hong Kong, $585-592$.

Lin, R. M., Lim, M. K., and Du, H. (1995), "Improved inverse eigensensitivity method for structural analytical model updating." Journal of Vibration and Acoustics, ASME, 117, 192-198 
Menn, C. (1996). “The place of aesthetics in bridge design.” Structural Engineering International, IABSE, 6(2), 93-95.

Mottershead, J. E., and Friswell, M. I. (1993). "Model updating in structural dynamics: a survey." Journal of Sound and Vibration, Academic Press, 167(2), 347-375.

Neville, A. M. (1982). Properties of Concrete, $3^{\text {rd }}$ Edition. Pitman Books Limited, London.

Pavic, A., Hartley, M. J., and Waldron, P. (1998). "Updating of the analytical models of two footbridges based on modal testing of full scale structures.” Proceedings of the $23^{\text {rd }}$ International Seminar on Modal Analysis, Leuven, Belgium, 1111-1118.

Rito, A. (1996). “Aesthetics and bridge design.” Structural Engineering International, IABSE, 6(2), 91-92.

SAS. (1997). ANSYS User Manual, Release 5.4. Swanson Analysis System, Inc., USA

Severn, R. T., Brownjohn, J. M. W., Dumanoglu, A. A., and Taylor, C. A. (1989). “A review of dynamic testing methods for civil engineering structures.” Civil Engineering Dynamics, University of Bristol Printing Unit, 1-24.

Takenouchi, K. (1998). “Single pylons for curved cable-stayed bridges.” Structural Engineering International, IABSE, 8(4), 269-272.

Tan, S. C. (1996). "Safti Link Bridge, design and construction." Defence Technology Group Seminars Series, MINDEF, Singapore. 
Troyano, L. F., Armisen, J. M., and Suarez, M. A. A. (1998). “The inclined towers of the Ebro and Lerez Bbridge.” Structural Engineering International, IABSE, 8(4), 258-260.

Xia, P. Q. (1999). “Condition assessment of bridges by dynamic measurements.” Technical Report, School of Civil and Structural Engineering, Nanyang Technological University, Singapore. 